\title{
Salvage robot-assisted radical prostatectomy with pelvic lymph node dissection after cryotherapy failure
}

\author{
Esequiel Rodriguez Jr · Douglas W. Skarecky • \\ Thomas E. Ahlering
}

Received: 18 October 2006/ Accepted: 18 December 2006/Published online: 19 January 2007

(C) Springer London 2007

\begin{abstract}
We report the first case of post-cryotherapy salvage radical prostatectomy for local recurrence performed laparoscopically with the da Vinci robot. Total operative time was 210 minutes and blood loss was $50 \mathrm{ml}$. There were no intraoperative or postoperative complications. The hospital stay was 24 hours and the Foley catheter was removed on postoperative day 7. The patient achieved a pad free status 4 weeks postoperatively. Pathology showed extensive disease, pT3bN0, Gleason score of $5+3$ and positive margins. The patient continued on complete androgen deprivation therapy and his follow up PSA at 10 months was $<0.1$. Further studies are needed to evaluate both functional and oncological results with this approach.
\end{abstract}

Keywords Robotics - Salvage prostatectomy ·

Cryotherapy

\section{Introduction}

We report the first case of post-cryotherapy salvage radical prostatectomy performed laparoscopically with the da Vinci robot.

\section{Case report}

A 52-year-old male was initially diagnosed and treated, at an outside hospital, with complete androgen depri-

E. Rodriguez Jr $(\bowtie) \cdot$ D. W. Skarecky ·

T. E. Ahlering

UCI Medical Center, Orange, CA, USA

e-mail: erodrigu@uci.edu vation therapy (ADT) for prostate cancer (cT2b, Gleason score $4+3$, PSA of $20 \mathrm{ng} \mathrm{ml}^{-1}$ ) in June 1999 . His PSA dropped to $0.1 \mathrm{ng} \mathrm{ml}^{-1}$, and he was subsequently treated with complete cryotherapy in March 2000. After cryotherapy treatment the PSA continued to rise (Table 1). In 2003 he was referred to our institution for salvage therapy after the PSA had risen to $23 \mathrm{ng} \mathrm{ml}^{-1}$. Re-biopsy confirmed persistent prostate cancer (Gleason $4+3=7$ involving 2/3 right sided cores occupying $60-80 \%$ of the specimen with intra and perineural involvement, and focal Gleason $3+3=6$ in $1 / 3$ cores involving the left apex and occupying $<10 \%$ of specimen). The prostate was slightly fixed on the right side on digital rectal examination. A metastatic work-up (bone scan, abdomen/ pelvis CT scan, ProstaScint scan, chest X-ray) was negative. A cystoscopy was not performed, because this is not part of our routine preoperative evaluation unless the patients have hematuria or severe lower urinary tract symptoms. The patient's AUA symptom score was 13 , bother score was 2 , and SHIM was 3 . The patient responded to four months of ADT (PSA $0.7 \mathrm{ng} \mathrm{ml}^{-1}$ ) and was counseled regarding salvage radiation therapy or radical prostatectomy (open and robotic). Our comfort level after 125 standard robotassisted laparoscopic prostatectomies (RALP) combined with our salvage post-radiation open surgery experience gave us confidence in offering a robotassisted prostatectomy as an alternative treatment.

Using our standard five-port technique the patient successfully underwent a planned wide excision nonnerve sparing salvage prostatectomy and lymphadenectomy; total operative time was $210 \mathrm{~min}$ and blood loss was $50 \mathrm{ml}$. There were no intraoperative or postoperative complications. The hospital stay was $24 \mathrm{~h}$ 
Table 1 Date, PSA value, and intervention

\begin{tabular}{lcl}
\hline Date & PSA $\left(\mathrm{ng} \mathrm{ml}^{-1}\right)$ & Intervention \\
\hline $3 / 1999$ & 19.7 & ADT started \\
$7 / 1999$ & 2.9 & \\
$3 / 2000$ & 0.1 & \\
$9 / 2000$ & 4.1 & \\
$1 / 2001$ & 6.0 & \\
$3 / 2001$ & 15.1 & \\
$12 / 2001$ & 15.2 & \\
$3 / 2002$ & 17.2 & ADT started \\
$9 / 2002$ & 15.2 & Salvage RALP \\
$4 / 2003$ & 23 & \\
$10 / 2003$ & 0.7 & \\
$10 / 2004$ & 0.1 & \\
\hline
\end{tabular}

and the Foley catheter was removed on postoperative day 7. Final pathological stage was pT3bN0, with a Gleason score of $5+3=8$. The tumor was extensively present in both right and left lobes, right and left apex, right and left bladder neck, right and left seminal vesicles, and extensive perineural invasion was noted. The tumor extensively penetrated through the prostatic capsule, with extracapsular extension. The prostatic pseudocapsule was not violated during the surgical resection. Margins were positive on the left and right side of the bladder neck, posterior apex, and on the right anterior and posterior surgical margins.

The patient returned to his referring urologist for further care and was continued on complete ADT. His follow up PSA 10 months postoperative was $<0.1 \mathrm{ng} \mathrm{ml}^{-1}$. The patient achieved pad-free status 4 weeks postoperatively. There have been no complaints to suggest bladder neck contracture, rectal complication, or lymphedema. The patient continues to be impotent.

\section{Discussion}

Salvage radical prostatectomy is a well-described treatment option for local recurrence after radiation therapy. Ten-year cancer-specific survival, overall survival, and disease-free survival rates of 70-75, 60-66, and $44-45 \%$, respectively, have been reported [1]. Salvage prostatectomy is associated with significant morbidity, however [1-3]. Rectal injuries at the time of surgery range from $0-35 \%$, urinary incontinence ranges from $30-60 \%$, and bladder neck contracture is reported in $0-28 \%$ of cases [1-3]. Vallencien and colleagues reported their experience with the laparoscopic approach noting comparable morbidity to the open approach, and less blood loss and postoperative pain [3].

Salvage prostatectomy after cryotherapy failure is not well documented. Grampsas and coworkers reported their results for six patients who underwent salvage radical perineal prostatectomy after cryotherapy. No intraoperative or postoperative complications were noted. Only one patient's PSA value failed to drop below $0.2 \mathrm{ng} \mathrm{ml}^{-1}$ after surgery. Operative time, blood loss, length of hospital stay, time to Foley catheter removal, and incontinence were not reported. Intraoperatively they noted increased fibrosis, adhesions, and distorted anatomy secondary to the cryodestruction. As far as we are aware, a salvage laparoscopic or robot-assisted radical prostatectomy after cryotherapy has not been reported. The cryotherapy resulted in extensive and dense adherence of the apex of the prostate to the muscle fibers of the urogenital diaphragm. From our experience with post-radiation open salvage surgery, the robot facilitated the sharp dissection necessary to free the prostate from the rectum. It is also our impression that the improved visualization augmented our confidence to dissect the apex and achieve adequate urethral length.

A primary goal with salvage therapy is complete elimination of disease. From our open post-radiation experience patients like this, with high PSAs $\left(>10 \mathrm{ng} \mathrm{ml}^{-1}\right.$ ) and advanced local disease, are not really candidates for cure. Given the patient's youth (56 years), however, and no other significant medical co-morbidities, the surgery was performed with the clear understanding that the primary goal was to reduce the disease and prevent local complications. This procedure was not performed with curative intent.

In summary, we report the first case of a salvage robot-assisted laparoscopic radical prostatectomy for local recurrence after cryotherapy and establish its feasibility. Further studies are needed to evaluate both functional and oncological results with this approach.

\section{References}

1. Chen BT, Wood DP (2003) Salvage prostatectomy in patients who have failed radiation or cryotherapy as primary treatment for prostate cancer. Urology 62:69-78

2. Grampsas SA, Miller GJ, Crawford ED (1995) Salvage radical prostatectomy after failed transperineal cryotherapy: histologic findings from prostate whole-mount specimens correlated with intraoperative transrectal ultrasound images. Urology 45:963-941

3. Vallancian G, Gupta R, Cathelineau X et al (2003) Initial results of salvage laparoscopic radical prostatectomy after radiation failure. J Urol 170:1838-1842 